\title{
Infection of the Western Flower Thrips, Frankliniella occidentalis, by the Insect Pathogenic Fungus Beauveria bassiana
}

\author{
Zhijian Zhang ${ }^{1}$, Changying Zheng ${ }^{1}$, Nemat O. Keyhani ${ }^{2}$, Yulin Gao ${ }^{3}$ and Junping Wang ${ }^{1, *}$ \\ 1 College of Plant Health and Medicine, Qingdao Agricultural University, Qingdao 266109, China; \\ zhijianzhang266@gmail.com (Z.Z.); zhengcy67@qau.edu.cn (C.Z.) \\ 2 Department of Microbiology and Cell Science, University of Florida, Gainesville, FL 32611, USA; \\ keyhani@ufl.edu \\ 3 State Key Laboratory for Biology of Plant Diseases and Insect Pests, Institute of Plant Protection, Chinese \\ Academy of Agricultural Sciences, Beijing 100081, China; gaoyulin@caas.cn \\ * Correspondence: junpingwang@qau.edu.cn
}

Citation: Zhang, Z.; Zheng, C.; Keyhani, N.O.; Gao, Y.; Wang, J. Infection of the Western Flower Thrips, Frankliniella occidentalis, by the Insect Pathogenic Fungus Beauveria bassiana. Agronomy 2021, 11, 1910. https://doi.org/10.3390/ agronomy11101910

Academic Editor: Noam Alkan

Received: 20 August 2021

Accepted: 19 September 2021

Published: 23 September 2021

Publisher's Note: MDPI stays neutral with regard to jurisdictional claims in published maps and institutional affiliations.

Copyright: (ㄷ 2021 by the authors. Licensee MDPI, Basel, Switzerland. This article is an open access article distributed under the terms and conditions of the Creative Commons Attribution (CC BY) license (https:// creativecommons.org/licenses/by/ $4.0 /)$.

\begin{abstract}
The western flower thrips, Frankliniella occidentalis, is an aggressive agricultural insect pest causing significant damage to a wide range of fruit, vegetable, and ornamental crops. Beauveria bassiana is a broad-host-range entomopathogenic fungus capable of infecting and killing F. occidentalis. Infection of thrips by B. bassiana strain BbYT12 using a concentration of $1 \times 10^{8}$ conidia $/ \mathrm{mL}$ resulted in $81.48 \%$ mortality in adults in $6 \mathrm{~d}\left(\mathrm{LT}_{50}=90 \pm 15.1 \mathrm{~h}\right)$. Scanning electron microscopy of the infection process revealed preferential adhesion and germination of fungal spores to inter-segmental folds or grooves on the insect body surface with penetrating germlings and extended hyphae visualized during the initial stages of infection (6-24 h). Histological analyses showed the appearance of in vivo hyphal bodies in sagittal sections and the fat body as early as $24 \mathrm{~h}$ post-infection. Within $72 \mathrm{~h}$, hyphal bodies and hyphae could be found throughout the infected organism including in the midgut, Malphigian tubules, alimentary canal, ovarioles (in females), and an extended hyphal network could be seen on insect cadavers ( $>72 \mathrm{~h}$ post-infection). Real-time RT-PCR analyses of the expression of select genes implicated in virulence including the $\operatorname{Pr} 1$ protease, beauvericin synthase, involved in the production of the secondary metabolite beauvericin, two cytochrome P450 monooxygenases implicated in cuticular hydrocarbon degradation, two multidrug efflux proteins, a perilipin involved in lipid storage, and the Hog1 MAP kinase and protein kinase A signaling factors revealed discrete patterns of infection-time dependent expression. These data provide basic insights into the process of B. bassiana infection of F. occidentalis.
\end{abstract}

Keywords: Beauveria bassiana; Frankliniella occidentalis; biopesticides; pathogenesis; histology; gene expression; real-time RT-PCR

\section{Introduction}

The broad-host-range insect pathogen, Beauveria bassiana, has long been recognized as a potential biological insecticide that could be incorporated into integrated pest management (IPM) practices for the control of thrips [1]. Interest in the use of B. bassiana as a biopesticide has led to its emergence as a model system for examining fungal development, stress response, and virulence [2,3]. Unlike most viral and bacterial pathogens, infection by $B$. bassiana is percutaneous, with fungal conidia (spores) attaching to the surface of the insect host and beginning the process of infection via penetration of the cuticle [4]. Successful mycosis involves the production of cuticle-degrading enzymes and toxins, formation of specialized infection structures, and production of hyphal bodies within the host hemocoel $[3,5,6]$. The fungus is capable of evading the host immune system to grow within host tissues, with fungal hyphae ultimately growing outwards to sporulate on the host cadaver [5-7]. Conidial adhesion and germination, appressorium production, and 
cuticle penetration are essential to the pathogenic nature of entomogenous fungi [8-10]. B. bassiana displays a wide host range allowing it to be used against vectors of humandisease-causing agents [11-14] and a wide range of agricultural pests [15].

The western flower thrips, Frankliniella occidentalis, is a highly destructive insect pest that can cause significant damage in greenhouse crops, a niche in which this insect is particularly adept at proliferating, especially as it displays a marked ability to develop resistance to a wide range of different chemical insecticides [1]. Because of its mixed diet, wide plant host range, and ability to transmit lethal plant viral diseases [16], F. occidentalis is regarded as an important economic pest [17-19]. In China, F. occidentalis was first discovered in greenhouses in Beijing in 2003 and is considered an invasive pest along with a number of other thrips species [20,21]. A significant amount of literature exists on attempts at using entomopathogenic fungi for control of F. occidentalis. Various formulations and the effects of environmental conditions and application methods (e.g., foliar versus soil) have been used to evaluate and develop programs for thrips control using insect pathogenic fungi [22-27]. These data suggest the high potential for effective control of thrips especially in greenhouse conditions. Although the histopathology of B. bassiana infection has been examined in a number of insects, e.g., Peregrinus maidis, Plutella xylostella, and Carposina sasakii larvae, much more limited information exists concerning the B. bassiana-F. occidentalis interaction and/or the contributions of specific fungal (virulence) genes and pathways to the infection process.

Here, we examined the infection of F. occidentalis by B. bassiana (strain BbYT12) that displayed high virulence towards the thrips. Scanning electron microscopy was used to examine a time course of fungal infection on the insect surface, including initial attachment, germination, and penetration of the host cuticle. Internal fungal growth including hyphal growth, hyphal body formation and proliferation, and the invasion of various host tissues by the fungus was followed via histological sectioning. The expression of a number of fungal genes including those involved in cuticle penetration, secondary metabolite synthesis, hydrocarbon and xenobiotic degradation, and cellular signaling was followed during discrete stages of the infection using Real-Time RT-PCR. These data form a basis for understanding the cellular and molecular factors involved in B. bassiana targeting of F. occidentalis.

\section{Materials and Methods}

\subsection{Entomopathogenic Fungi and Insects}

B. bassiana strains BbYT12, 13, and 14 were obtained from infected giant scale insects (Drosicha corpulenta, Kuwana). Fungal strains were cultured on SDAY (4\% glucose, 1\% yeast extract, $1 \%$ peptone, and $2 \%$ agar, $\mathrm{pH} 6.0 \pm 0.1$ ) at $25^{\circ} \mathrm{C}$ for $7 \mathrm{~d}$. Typically, conidia were harvested from the surface of the agar plates into a sterile $0.1 \%$ Tween- 80 solution. Conidial suspension concentrations were determined using a hemocytometer and adjusted to $1.0 \times 10^{8}$ conidia/mL with a $0.1 \%$ Tween- 80 solution as needed. Female adults of F. occidentalis were reared on clover (Trifolium repens L.) at Qingdao Agricultural University. F. occidentalis were fed on kidney bean (Phaseolus vulgaris L.) and purple cabbage (Brassica oleracea L.) at $25 \pm 0.5^{\circ} \mathrm{C}$ and $50-60 \%$ relative humidity $(\mathrm{RH})$ with a photoperiod of 16:8 (light:dark) in the laboratory.

\subsection{Insect Bioassays Using F. occidentalis}

Adult F. occidentalis were randomly placed into inside insect-rearing boxes containing purple cabbage as food. Adult F. occidentalis were inoculated with fungal spores by direct spray application of $1.5 \mathrm{~mL}$ of the conidial suspension using an Aldrich chromatography sprayer (deposits of sprayed conidia: $510-525$ conidia $/ \mathrm{mm}^{2}$ ). Control insects were treated with sterile $0.1 \%$ Tween- 80 . At least fifty F. occidentalis adults were selected and put into the insect-rearing box. Following inoculation, the insects were transferred to rearing chambers at $25 \pm 0.5^{\circ} \mathrm{C}$ and $85 \pm 5 \% \mathrm{RH}$ with a photoperiod of 16:8 (L:D). Every treatment contained three replicates. 


\subsection{Histopathological Observations}

\subsubsection{Light Microscopy}

Frozen sections of $F$. occidentalis adults were collected $4,8,12$, and $18 \mathrm{~h}$ after inoculation by the fungal conidia. For each observation period, approximately 30 insects were fixed in $10 \%$ formaldehyde buffer for $24 \mathrm{~h}$. After fixation, the samples were dehydrated in a graded series (20 and 30\%) of sucrose solutions and embedded in embedding medium. Embedded specimens were serially sectioned to $10 \mu \mathrm{m}$ thicknesses by a manual freezing microtome, mounted on glass slides, and stained with hematoxylin and eosin. Samples were covered with neutral balata and observed under an Olympus microscope. Paraffin sections: At 24, 48, 72, 96, and $120 \mathrm{~h}$ post-inoculation, live and dead insects were selected from the samples and rinsed using phosphate-buffered saline (PBS). The rinsed samples were gradually dehydrated in a series of ethanol solutions $(35,55,75,85,95$, and $100 \%(v / v))$ and xylene infiltrated $(35,55,75,85,95$, and $100 \%)$ for $20 \mathrm{~min}$ at each level. The samples were embedded in xylene:paraffin $(1: 1, v / v)$ for $24 \mathrm{~h}$ at $56^{\circ} \mathrm{C}$ and embedded in paraffin for $48 \mathrm{~h}$ at $56^{\circ} \mathrm{C}$. The embedded specimens were serially sectioned into $8 \mu \mathrm{m}$ slices using a Leica microtome. The sections were mounted on glass slides and stained using Grocott's methenamine silver stain (counterstained with light green) [28]. Slides were enclosed in neutral balsam, and the slide preparations were observed under an Olympus microscope.

\subsubsection{Scanning Electron Microscopy}

At $1,4,8,12,18$, and $24 \mathrm{~h}$ post-inoculation, approximately 15 insects for each observation period were collected and immersed in $4 \%(v / v)$ glutaraldehyde $(\mathrm{pH} 7.2,0.2 \mathrm{M}$ phosphate buffer) for $48 \mathrm{~h}$ at $4{ }^{\circ} \mathrm{C}$. After rinsing three times with $0.2 \mathrm{M}$ phosphate buffer, the rinsed samples were dehydrated in a gradient of ethanol solutions (30\% to $100 \%)$ for $15 \mathrm{~min}$ at each level. Then, tert-butyl alcohol was used to displace the ethanol. Samples were dried by critical point drying, coated with a gold palladium film, and examined and photographed using a scanning electron microscope (7500F, JEOL, Tokyo, Japan).

\subsection{Genes Expression Analyses by Real-Time Reverse Transcription RT-PCR}

F. occidentalis were infected with $B$. bassiana conidial suspensions $\left(1 \times 10^{8}\right.$ conidia/mL $)$ as above. Samples of treated and control untreated adults were collected at 4, 8, 12, 18, 24, 48,72 , and $96 \mathrm{~h}$ post-infection (at least 50 adults in each sample). Three samples were used for each treatment at a given time point. Total RNA from a sample was isolated using Trizol reagent (Invitrogen, Carlsbad, CA, USA). Briefly, $1 \mathrm{~mL}$ of the Trizol reagent was added to 50-100 $\mathrm{mg}$ of tissues and homogenized using a mortar and pestle. After homogenization $0.2 \mathrm{~mL}$ of chloroform was added to the suspension and mixed by shaking. After 2-3 min, the sample was centrifuged $\left(12,000 \times g, 15 \mathrm{~min}, 4^{\circ} \mathrm{C}\right)$ and the resultant RNA precipitated from the upper aqueous phase using isopropanol. Synthesis of cDNA and real-time RT-PCR were performed according to the manufacturer's instructions (PrimeScript $\mathrm{H}^{\mathrm{RT}}$ reagent Kit with gDNA Eraser, TaKaRa). A total of 12 genes related to adhesion, appressorium formation, and penetration were selected for expression profiling by RT-PCR. Actin was used as an internal control. Primer sequences for amplification of indicated genes are given in Table 1. All real-time RT-PCR experiments included three replicates and the experiments were performed using three biological replicates.

\subsection{Statistical Analysis}

All experiments were repeated at least three times. For real-time RT-PCR experiments, expression levels between the groups were analyzed by the $2^{-\triangle \triangle \mathrm{CT}}$ method [29]. Briefly, CT values provided from real-time RT-PCR experiments (triplicate samples for each data point) were analyzed for the change in expression using the equation, $\Delta \Delta C_{T}=\left(C_{T, \text { Target }}-C_{T, A c t i n}\right)_{T i m e x}-\left(C_{T, T a r g e t}-C_{T, A c t i n}\right)_{T i m e 0}$. All data were analyzed by one-way analysis of variance (ANOVA) using SPSS19.0 and the LSD test to compare differences between treatments. 
Table 1. Primers used in this research.

\begin{tabular}{|c|c|c|c|}
\hline Gene & Gene Accession & Sequence $\left(5^{\prime}-3^{\prime}\right)$ & Sequence $\left(3^{\prime}-5^{\prime}\right)$ \\
\hline $\begin{array}{l}\text { ATP-binding cassette } \\
\text { transporter (Pdr5) }\end{array}$ & BBA_07660 & TCCTGCCCTTCTTCCTCGTCATG & AGAGCACGCCGCCGACATAG \\
\hline $\begin{array}{l}\text { ATP-binding cassette } \\
\text { transporter (Pdr2) }\end{array}$ & BBA_08779 & CGACGAGACGCAGGTTCATTCTTC & GACAGCCGAAGGAGCCAATGC \\
\hline $\begin{array}{c}\text { Protein kinase A } \\
\text { cAMP-dependent subunit }\end{array}$ & BBA_05916 & CATCAGGCAAGTCCGTCCAG & TGCTGCGTGTTCATTAGGTTG \\
\hline $\begin{array}{l}\text { Cuticle-degrading protease } \\
1(\operatorname{Pr} 1)\end{array}$ & BBA_00443 & AGACAGTGGCTCGGGTTCG & TCTGGGCGGCATCCCTATT \\
\hline $\begin{array}{l}\text { Beauvericin biosynthetic } \\
\text { protein }\end{array}$ & BBA_09727 & TAAAGGGACTCGACATGCTCA & GGGGTCACTTGTATCAATCTTGTAC \\
\hline$\beta-1,3$ Glucan synthase & BBA_10207 & CCGCTGTATCCCACGAAATG & AAGAACGGTGACAGGGAGCA \\
\hline Perilipin homolog 1 & BBA_08759 & CAACGTCGAGGGCTCTGTC & CGGCGAAGGTCTTGTAGGC \\
\hline $\begin{array}{l}\text { Mitogen-activated protein } \\
\text { kinases hog1 }\end{array}$ & BBA_01244 & TGAGCGGGAAGCCCTTGTT & GACGTGTCGGCGAATAGCG \\
\hline $\begin{array}{c}\text { Cytochrome P450 } \\
\text { Monooxygenase CYP52 } \times 1\end{array}$ & GU566074 & ACCGCAACCCGAAACCAATC & CCGAATATCCAATATCCTGTCCCT \\
\hline $\begin{array}{c}\text { Cytochrome P450 } \\
\text { Monooxygenase CYP5293A }\end{array}$ & BBA_04705 & GCTTCGCCGGCATGTCG & CAACCTCGTCATCTAGCGTCACTG \\
\hline Cytochrome c synthase & BBA & CGAAGCGGTAGTTAGAAGGTGC & CGACATTTTGCTCGACTCTGAAG \\
\hline Actin & BBA_04860 & АСССТCСGCTACСCCATTG & CGGGGGCGTTGAACGTCT \\
\hline
\end{tabular}

\section{Results}

3.1. Insect Mortality and Fungal Attachment to the Insect Body

Three different B. bassiana strains, BbYT12, 13, and 14, isolated from scale insects, were used in laboratory bioassays to determine the rate of mortality against $F$. occidentalis (Figure 1). For BbYT12, the calculated mean lethal time to kill $50 \%$ of the insect hosts $\left(\mathrm{LT}_{50}\right)$ using $1 \times 10^{8}$ conidia $/ \mathrm{mL}$ was determined to be $90 \pm 15.12 \mathrm{~h}$. Accurate $\mathrm{LT}_{50}$ values could not be determined for the other two strains due to lower mortality levels. As strain BbYT12 showed the highest virulence, it was used in all subsequent experiments.

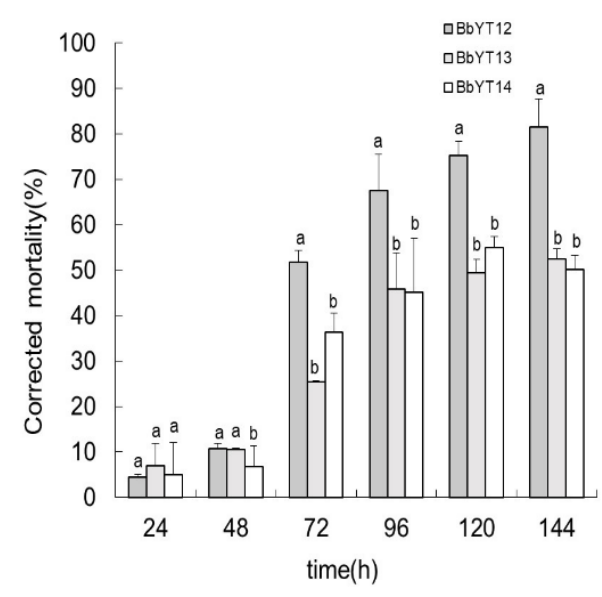

Figure 1. Insect bioassays. Time course of corrected mortality of F. occidentalis infected with B. bassiana. Data were subjected to one-way ANOVA for each isolate at a given time point. Means in each column within each isolate followed by the different letter indicate significant difference at $p<0.05$. Error bars $=$ standard deviation .

In order to examine the initial events during the interaction between B. bassiana and F. occidentalis, scanning electron microscopy was used. After spray application of the fungal conidia, high spore densities were seen $(1 \mathrm{~h}$ p.i.) in the regions that included the intersegmental folds, grooves on the body surface, and at the boundaries of different body parts, such as the head, thorax, and abdomen, with lower spore densities seen in other 
regions of the body. With respect to the thrips' head region, conidia could be seen attached to antennae, around the mouthparts, and surrounding the compound eye (Figure 2A-C). In a magnified view, several grooves, as well as surface roughness, could be observed around the conidia at the basal area of the head (Figure 2D). Fungal conidia were found attached throughout the body surface, although relatively higher concentrations could be seen at the thorax (Figure 2E), where they were deposited in areas near the setae and at the base of the legs (Figure 2F). Masses of conidia were also observed on the intersegmental folds and at the end of the abdomen (Figures 2G,H and 3A), with fewer conidia observed on the alinotum. High conidial densities were seen on the wings, particularly at the base of the wings (Figure 3B,C). Furthermore, conidia were distributed over the cuticle, on the surfaces of the feet and the propodium, and around the apotelus (Figure 3D-F). In addition, B. bassiana conidia were found to be able to adhere to the smooth surfaces around the setae (Figure 3G), and large numbers of conidia were observed between the pereiopoda and metapedes (Figure $3 \mathrm{H}$ ).

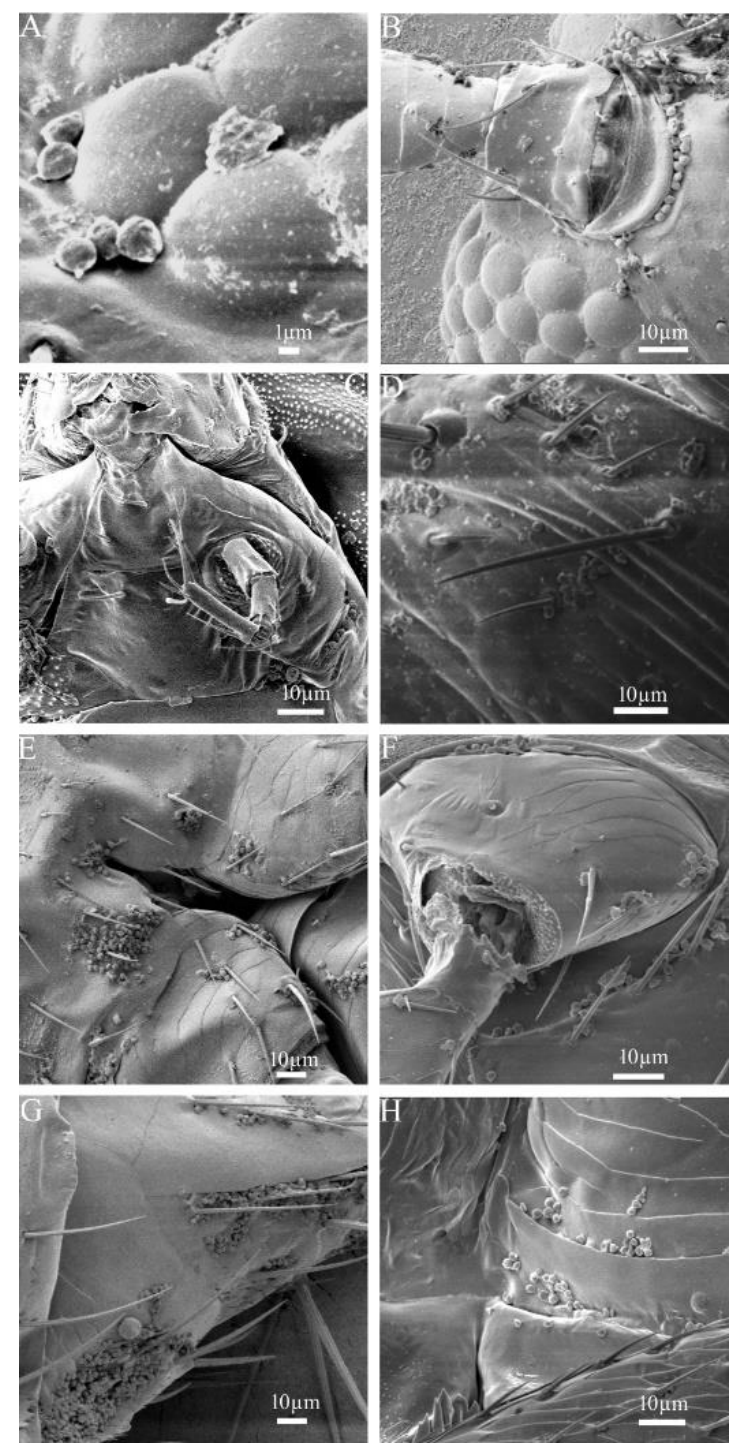

Figure 2. Representative scanning electron micrographs (SEMs) of the fungal infection process. B. bassiana fungal conidia visualized: (A) between the ommatidia of the compound eye, (B) on the antenna, (C) around the mouthparts, (D) on the basal area of the insect head, (E) attached to the thorax, (F) around the base of the legs, $(\mathbf{G})$ at the end of the host abdomen, and $(\mathbf{H})$ on the intersegmental folds in the abdomen. 


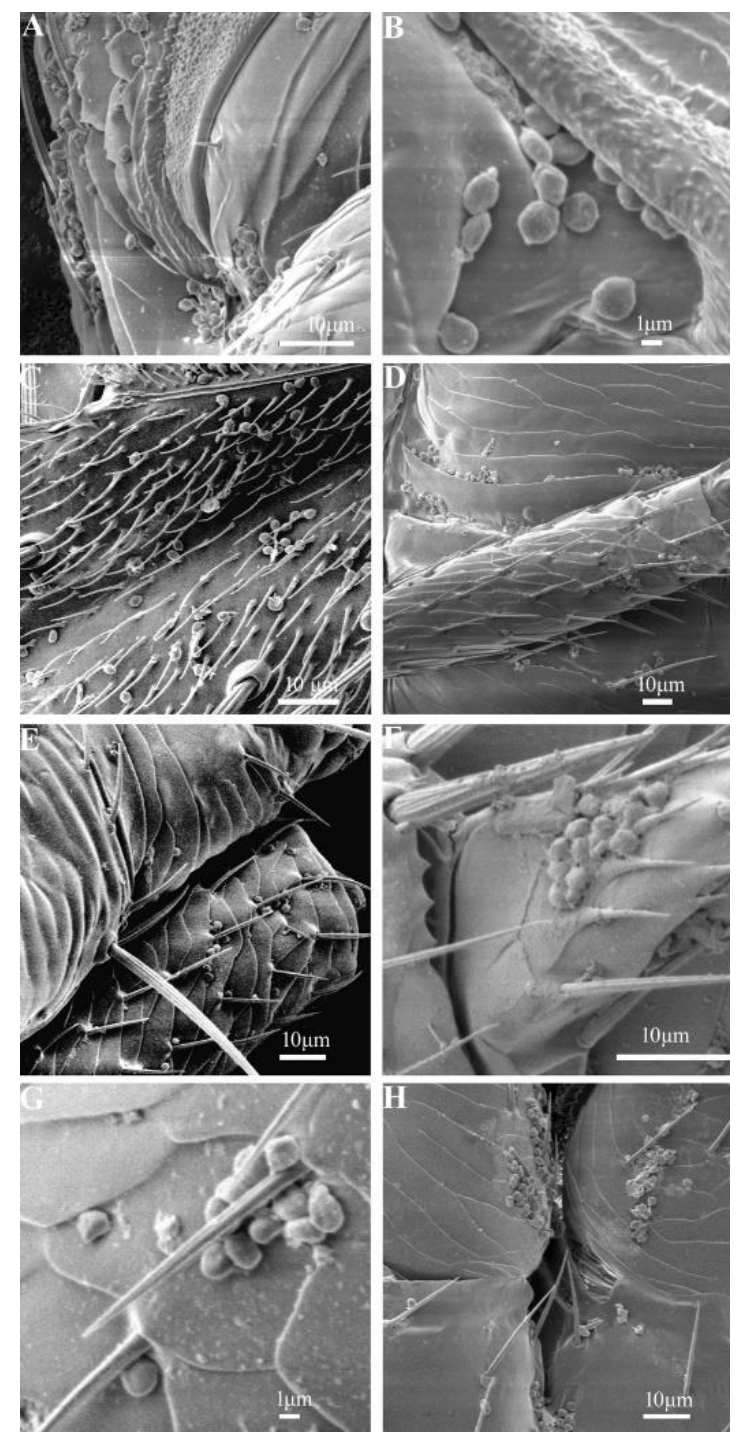

Figure 3. Representative SEM images of the fungal infection process. B. bassiana conidia visualized: (A) on the insect cuticular folds, (B) at the base of the wings, (C) attached to the wings, (D) on the surface of the insect legs/feet, (E) on the propodium, (F) at the apotelus, (G) around the setae, and (H) adhering between the pereiopoda and metapedes.

\subsection{Conidial Germination and Penetration of the Insect Cuticle}

Within $4 \mathrm{~h}$ of inoculation on the insects, B. bassiana germ tubes could be seen, often oriented such that they appeared to be in the process of penetrating the host cuticle. Within this time frame ( $4 \mathrm{~h}$ p.i.), $\sim 83 \%$ of the conidia had germinated (Figure $4 \mathrm{~A}$ and Table 2 ), with clear indications of some of the germinated conidia beginning to penetrate the integument (Figure 4B). In several instances "excavation" of the cuticle was apparent (Figure 4C). Within 8 h p.i., almost $100 \%$ of the conidia had germinated (Figure 4D). Most conidia produced a single, short germ tube, although bipolar germination could be seen in a

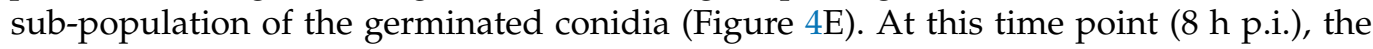
proportion of cuticle-penetrating germ tubes/hyphae appeared to be $>80 \%$ (Figure $4 \mathrm{~F}$ ). In some instances shriveled conidia could be seen, although whether this may be due to fixation is unknown (Figure 4I). 

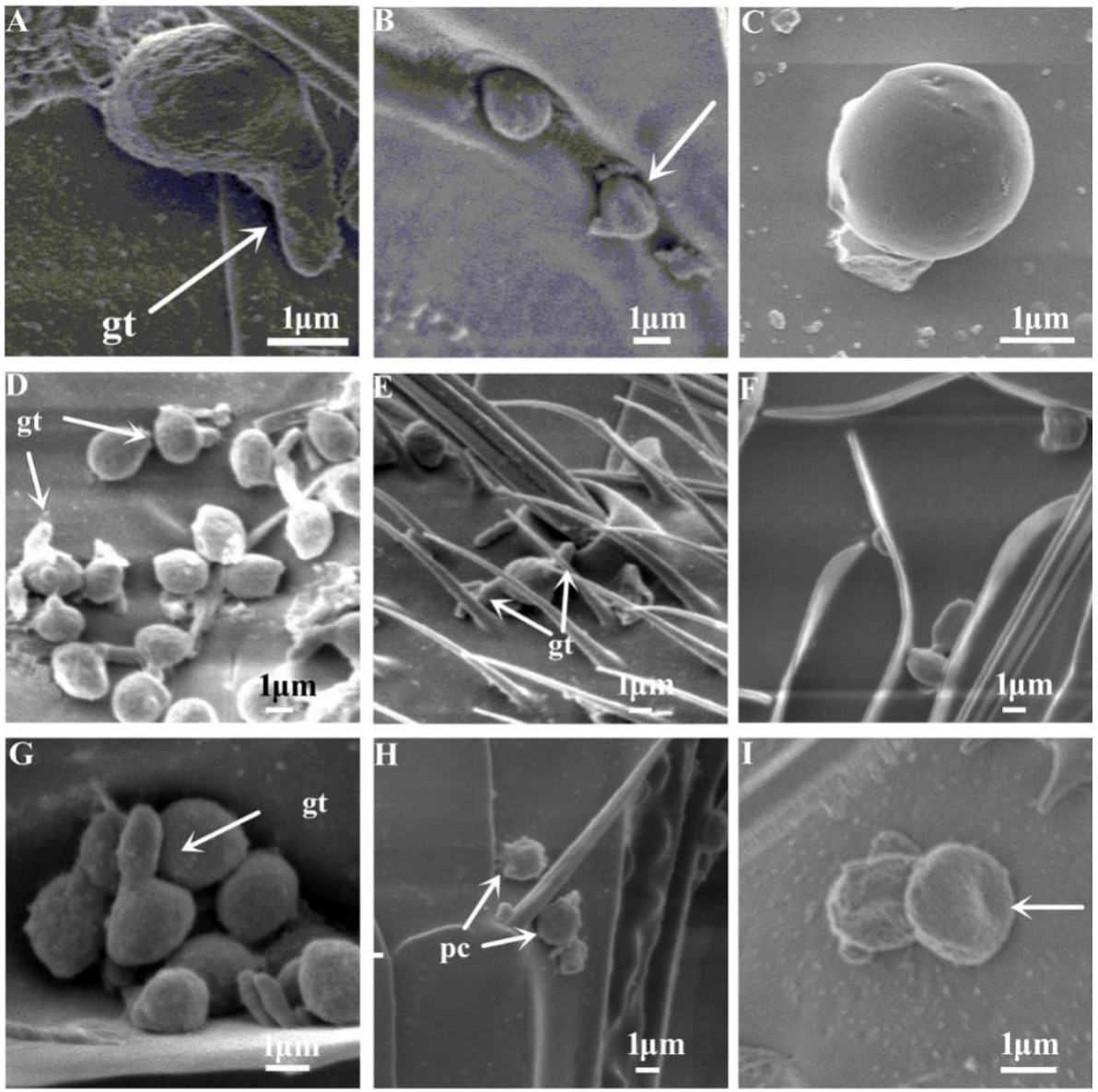

Figure 4. Representative SEM photographs of B. bassiana attachment, germination, and penetration of the F. occidentalis cuticle. (A) Fungal germ tube (gt) formation $4 \mathrm{~h}$ post-inoculation (p.i.), (B) fungal penetration of the integument, $4 \mathrm{~h}$ p.i., (C) fungal penetration of the cuticle, $4 \mathrm{~h}$ p.i., (D) conidial germination 8 h p.i., (E) bipolar conidial germination, 8 h p.i., (F) fungal cuticle penetration/penetrating conidia (pc), 8 h p.i., (G) conidial germination, 8 h p.i., (H) cuticle penetration, $8 \mathrm{~h}$ p.i., and (I) shriveled penetrating conidia.

Table 2. Quantification of discrete morphological infection stages of B. bassiana on the cuticle of F. occidentalis.

\begin{tabular}{ccccc}
\hline Rate (\%) & \multicolumn{4}{c}{ Time (Post-Inoculation, h) } \\
& $\mathbf{4}$ & $\mathbf{8}$ & $\mathbf{1 2}$ & $\mathbf{1 8}$ \\
\hline Germination & $82.69 \pm 1.33$ & $100+0$ & $100+0$ & $100+0$ \\
Penetration & $46.15 \pm 1.26$ & $82.26 \pm 0.61$ & $100+0$ & $100+0$ \\
Shriveling & $0+0$ & $51.61 \pm 1.22$ & $57.41 \pm 0.71$ & $67.38 \pm 0.82$ \\
\hline
\end{tabular}

Note: approximately 15 insects for each observation period.

At the $8 \mathrm{~h}$ p.i. time point, few ungerminated conidia were detected on the cuticle surface (Figure $5 \mathrm{~A}$ ), whereas mucilage and penetrating structure began to be evident (Figure 5B). After $12 \mathrm{~h}$, many conidia appeared blended into the cuticle due to the production of an apparent mucilaginous coat around the conidia and germ tube, and penetrating conidia were increasingly found (Figure 5C and Table 2). Intriguingly, at this time point $\sim 55 \%$ of the conidia appeared shriveled (Figure 5D). A similar pattern was seen at the $18 \mathrm{~h}$ post-inoculation time points, with mucilage around penetrating conidia (Figure 5E,G). At $18 \mathrm{~h}$ p.i., most conidia appeared to be in the process of penetrating the cuticle, and the proportion of shriveled conidia increased to $\sim 67 \%$ (Table 2). 

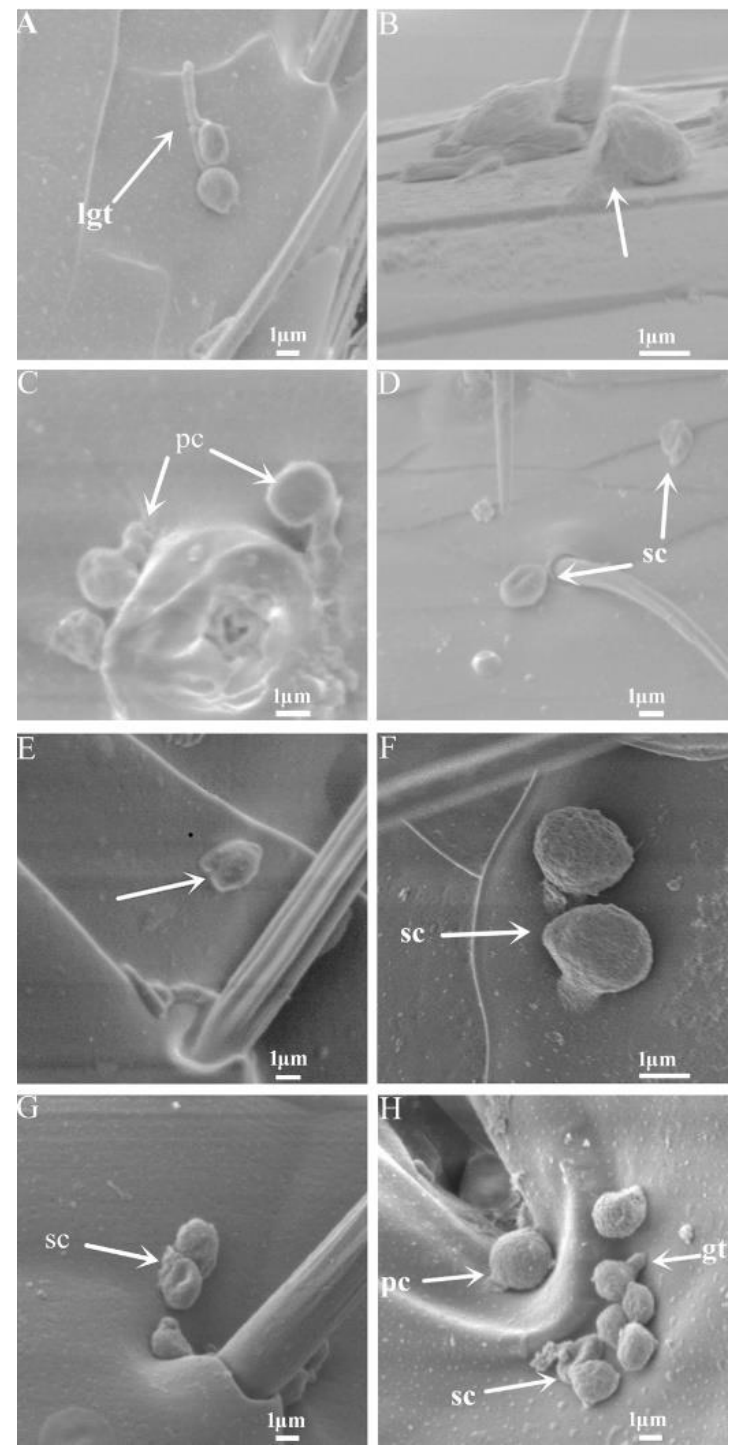

Figure 5. Representative SEM photographs of B. bassiana germ tubes, penetration, and shriveled conidia on the surface of F. occidentalis. (A) B. bassiana long germ tubes (lgt), $8 \mathrm{~h}$ p.i., (B) fungal mucilage production, $12 \mathrm{~h}$ p.i., (C) penetrating conidia (pc), $12 \mathrm{~h}$ p.i., (D) shriveled conidia (sc), $18 \mathrm{~h}$ p.i., (E) fungal mucilage production, $18 \mathrm{~h}$ p.i., (F) penetrating and shriveled conidia, $18 \mathrm{~h}$ p.i., (G) shriveled conidia, $18 \mathrm{~h}$ p.i., and (H) fungal germ tubes, penetrant structures, and shriveled conidia, 18 h p.i.

\subsection{Histopathology: Fungal Hyphal Body Proliferation Inside the Insect Host}

Sectioning of B. bassiana-infected F. occidentalis revealed extensive invasion of the insect internal tissues. Transition from hyphal growth to the production of fungal hyphal bodies (yeast-like cells), was apparent inside the insect body and hemocoel at $12 \mathrm{~h}$ p.i., with an increased number of hyphal bodies seen at 18 and $24 \mathrm{~h}$ p.i. (Figure 6A). At $24 \mathrm{~h}$ post-inoculation, hyphal bodies could be seen surrounding and invading the insect fat body (Figure 6B). At $48 \mathrm{~h}$ p.i., a few dead F. occidentalis could be seen ( 10\%). Hyphal growth increased in dead insects as compared to those remaining alive, which had greater proportions of hyphal bodies (Figure 6C,D). Post-mortality, the entire bodies of insect cadavers appeared overrun with fungal hyphae ( $72 \mathrm{~h}$ p.i., $\sim 50 \%$ mortality). Within the 24-72 $\mathrm{h}$ time points, the insect midgut and the Malpighian tubules were filled with hyphal bodies (Figure 6E,F), and invasion of the alimentary canal (Figure 6G) and the reproductive system (Figure $6 \mathrm{H}$ ) was evident. At $96 \mathrm{~h}$ p.i., in those insects still alive, hyphal bodies could be seen overgrowing the insect body (Figure 7A), and covering the midgut and the lateral 
oviducts (Figure 7B). In addition, hyphal invasion of the ovaries in both live insects and dead insects could be seen. Extensive hyphal growth covering the bodies of both cadavers, and in some instances living insects, could also be seen (Figure 7C).
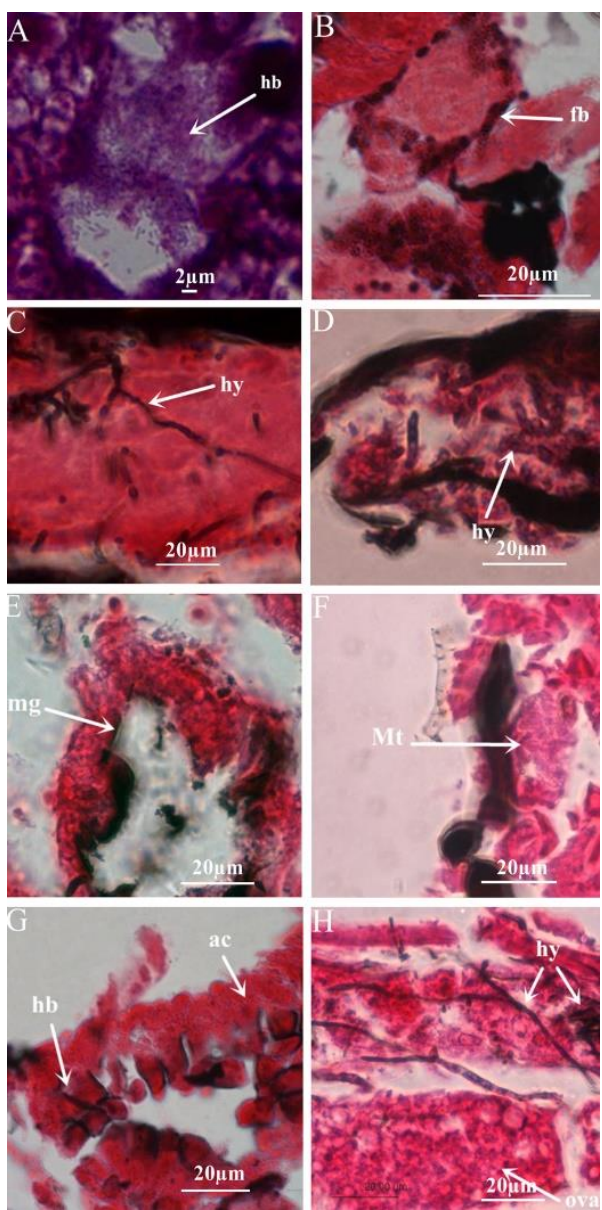

Figure 6. Representative histopathological images of $B$. bassiana infection of $F$. occidentalis. (A) B. bassiana hyphal bodies (hb) inside F. occidentalis, $12 \mathrm{~h}$ p.i., (B) fungal hyphal bodies surrounding the insect fat body (fb), $24 \mathrm{~h}$ p.i., (C) fungal hyphae (hy) in the live insects, $48 \mathrm{~h}$ p.i., (D) hyphal network in dead F. occidentalis, $48 \mathrm{~h}$ p.i., (E) insect midgut (mg) filled with the hyphal bodies, 72 h p.i., (F) insect Malpighian tubules (Mt) with fungal hyphal bodies, $72 \mathrm{~h}$ p.i., (G) hyphal bodies in the insect alimentary canal (ac), $72 \mathrm{~h}$ p.i., and (H) fungal invasion of insect ovariole (ova) 72 h p.i.
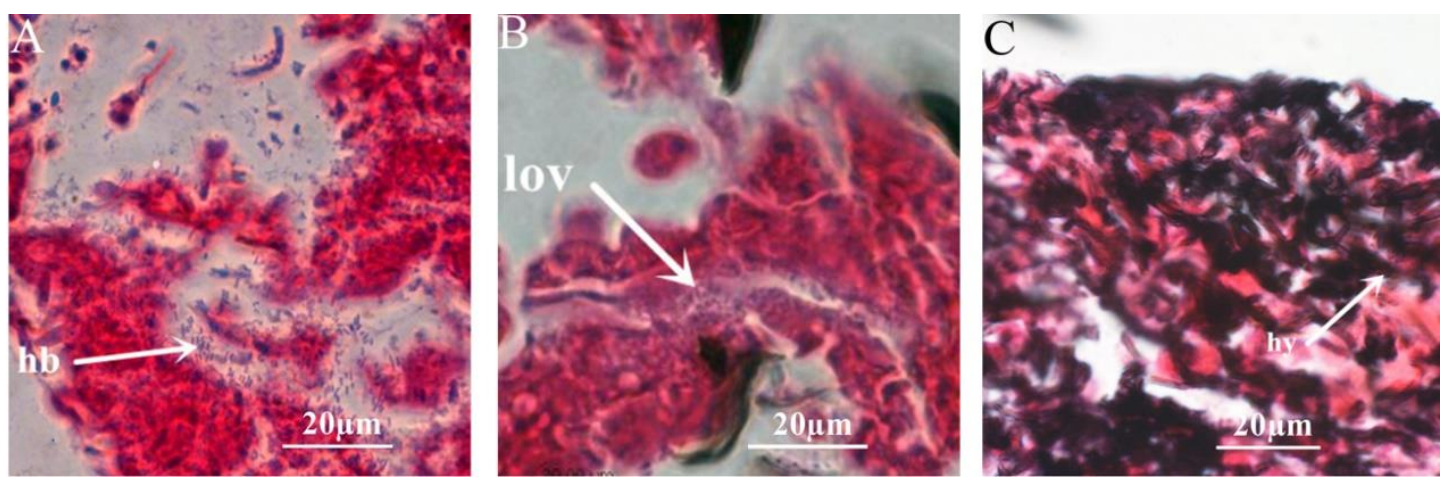

Figure 7. Representative histopathological images of sagittal sections of F. occidentalis infected with B. bassiana, (96 h p.i.). (A) Extensive hyphal bodies proliferation in the insect body, (B) hyphal bodies in the lateral oviducts (lov), and (C) insect cadavers covered with hyphae. 


\subsection{Expression of Fungal Virulence-Related Genes during the Infection Time Course}

In order to examine the expression of virulence-related genes in B. bassiana during infection of $F$. occidentalis, the expression of 12 genes was examined during the infection process (Table 1). These genes included the $\operatorname{Pr} 1$ protease, beauvericin synthase, cytochrome P450s CYP52X1 and CYP5293A, perilipin, cytochrome c synthase, the Hog 1 MAPK, protein kinase A cAMP-dependent subunit, the multidrug efflux proteins, $P d r 2$ and $P d r 5$, and $\beta-1,3$ glucan synthase. After normalization to actin expression levels, candidate genes were separated into three groups based upon expression levels for scaling and visualization purposes. Beauvericin synthase and CYP52X1 showed the highest levels of expression at early infection time points, with beauvericin synthase expression induced $\sim 35-40$ fold $12 \mathrm{~h}$ p.i., and CYP52X1 20-25 fold $18 \mathrm{~h}$ p.i. (Figure $8 \mathrm{~A}$ ). $P d r 5$, the $\operatorname{Pr} 1$ protease, and $\beta-1,3$ glucanase expression levels similarly peaked at $\sim 18 \mathrm{~h}$ p.i. (5-7-fold above the initial $4 \mathrm{~h}$ p.i. time point), with expression of the latter gene typically $2-3$-fold induced (as compared to the $4 \mathrm{~h}$ p.i. time point) over most of the time course examined (Figure 8B). In contrast expression of CYP5293A was highest at the 12 and $24 \mathrm{~h}$ (peak) p.i. time points (3-6-fold), with lower levels seen at the other time points. Expression of the protein kinase A cAMP-dependent subunit peaked at $\sim 72 \mathrm{~h}$ p.i., whereas the perilipin showed high expression from the 24 to $72 \mathrm{~h}$ p.i. time points (Figure 8C). Maximal expression of the Hog1 MAP kinase was seen at the $48 \mathrm{~h}$ p.i. time point, with cytochrome c synthase levels low throughout the time course.
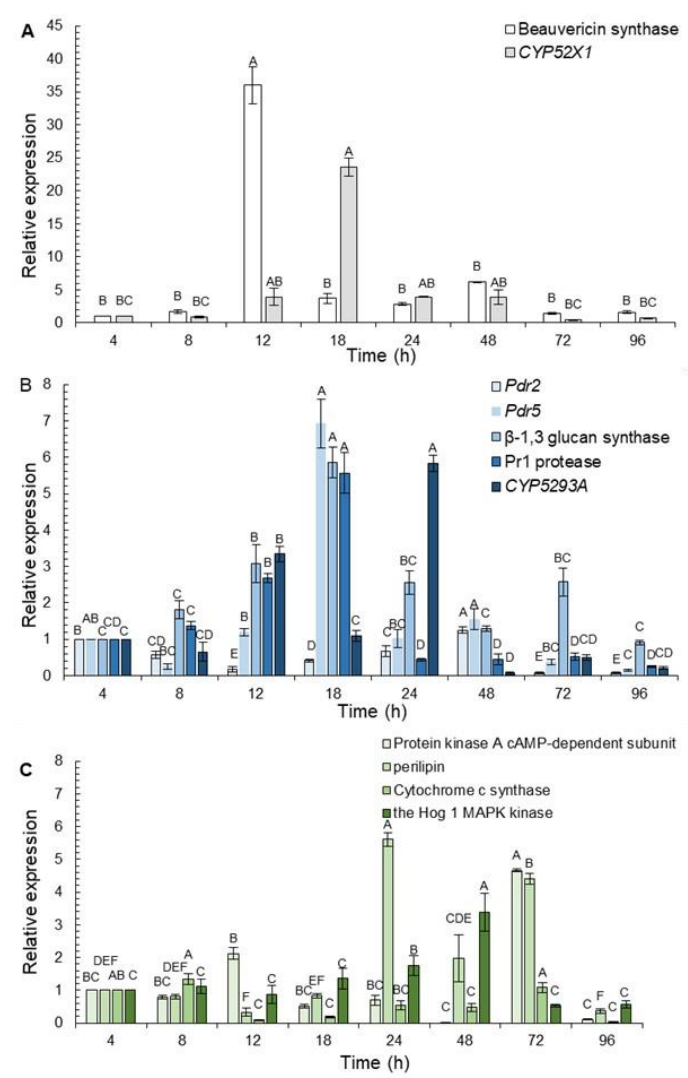

Figure 8. Time course of B. bassiana gene expression during infection of F. occidentalis. The expression of select fungal genes implicated in the infection process was quantified by real-time RT-PCR as detailed in the Materials and Methods section. Means in each column within each gene followed by a different letter indicate significant difference at $p<0.05$. Relative gene expression represents the $\log$ fold change, $2^{-\triangle \Delta C T}$. (A) Expression profiles of B. bassiana beauvericin synthase and CYP52X1. (B) Expression profiles of B. bassiana Pdr2, Pdr5, $\beta$-1,3-glucan synthase, Pr1 protease, and CYP5293A. (C) Expression profiles of B. bassiana protein kinase A cAMP dependent subunit, perilipin, cytochrome C synthase, and Hog1 MAPK. 


\section{Discussion}

Insect management using living biological control agents differs significantly from the use of chemical pesticides. Chemical pesticides tend to directly target specific physiological processes, resulting in death of the host in a relatively short period of time (min to $\mathrm{h}$ ) after contact. Chemical pesticides tend to have broad non-target and potential detrimental human health and environmental effects. In contrast, microbial biological control agents, and insect pathogenic fungi in particular, have significantly lower non-target effects and are not pathogenic towards vertebrates, with overall lower environmental and human health risks [30]. However, most microbial agents can only optimally function under appropriate environmental and handling conditions, and the process of infection and mortality is on a longer time scale (days) as compared to chemical insecticides. Thrips are a major agricultural pest, and the use of chemical pesticides has led to the emergence of resistant populations [1]. Thus, the use of the entomopathogenic fungus B. bassiana has been investigated either alone or in combination with chemical pesticides for thrips control [31,32]. In order to gain a better understanding of the process of B. bassiana infection of thrips, we have performed a histological examination of the infection process and examined the expression of select fungal genes implicated in virulence during a time course of infection of $F$. occidentalis.

The initial attachment of fungal conidia to the surface of the insect body depends on a combination of hydrophobic interactions and consolidation of attachment [33,34]. Our data show that conidia of B. bassiana strain BbYT12 were capable of binding to any site on the cuticle of adult $F$. occidentalis, although some preference were observed particularly to the surfaces of the setae, intersegmental folds, and grooves, a finding similar to what has been reported by others [35]. Conidia were frequently trapped by the setae, possibly because the environment of the setae is more humid as a result of their association with respiratory transpiration processes $[36,37]$ These conditions would be beneficial for conidial germination, thus increasing the activity of the fungus. The pathogenic activity of $B$. bassiana has been shown to be enhanced in high humidity when infecting Phaedon brassicae Baly (Coleoptera: Chrysomelidae) and Bemisia tabaci nymphs [38] and humidity has been identified as an important factor for targeting F. occidentalis $[23,24]$. A large number of conidia were also seen gathered near the compound eye and around the mouthparts, similar to what has been observed during B. bassiana infection of C. sasakii larvae. Consolidation of adhesion via production of mucilage is known to play an important role in the adhesion of fungal spores to a wide range of hosts including plants, animals, and insects $[34,39,40]$. For insect pathogenic fungi, mucilage was found around spores that were penetrating the integument [41]. Here, we also observed mucilage around adhering and penetrating conidia/germ tubes. Examination of the adhesion of Lecanicillium lecanii adhered to the epicuticle of thrips, aphids, and mealybugs, revealed the secretion of dense mucilage during attachment [42,43]. In addition to promoting tighter attachment, mucilage may also serve as a vehicle for delivery of cuticle-degrading enzymes [44].

Our data show that within $8 \mathrm{~h}$ of infection, the B. bassiana conidia had germinated, and germ tubes and penetrating hyphae could be seen as early as $4 \mathrm{~h}$ post-infection (p.i.). Over time, an increase in penetrating hyphae was observed as well as a "shriveling" of the conidia and penetrating germlings. This shriveling was notable as a reduction in $20-50 \%$ of the size of the cells was seen as well as distortions in the overall cellular morphology. While it cannot be excluded that these changes were due to sample fixation effects, these observations appear to indicate important changes in either the overall stability of the infecting/penetrating cells and/or in membrane components. Whether this is a consequence of the infection process or due to stress/host defense responses remains to be determined. Overall, the progression of germination and penetration agree with reports of others [45], as well as instances of bipolar germination and some specialized routes of entry, e.g., germinating conidia on F. occidentalis wings and germ tube penetration of the 
cuticle through sockets at the base of bristles/hair situated on the forewing veins, the latter similar to what has been seen for B. bassiana penetration of the cuticle of elaterid larvae [46].

Fungal hyphal body production and proliferation inside the host was apparent within $24 \mathrm{~h}$ p.i., rapidly spreading to other tissues after $24-36 \mathrm{~h}$ p.i., where extensive fungal growth could be seen. An examination of Leptolegnia chapmanii infection of Aedes aegypti indicated invasion of host fat body tissues within 1-2 d of infection [42,46], and in our study, hyphal bodies surrounding the F. occidentalis fat body and host melanization responses (blackening of tissues) could be seen as early as $24 \mathrm{~h}$ p.i. Fungal cells were capable of rapidly infecting additional tissue including the alimentary canal, Malpighian tubules, and muscle tissues. Over time ( $>36 \mathrm{~h}$ ) hyphae and hyphal bodies could be seen colonizing ovaries and other tissues, similar to what has been reported for Isaria fumosorosea infection of Bemisia tabaci [47].

Here, we also examined the expression patterns of a number of fungal genes implicated in virulence over the time course of infection. Secondary metabolites are known to impact infection and the expression of beauvericin synthase was induced over 35-fold during the time course examined, with peak expression seen at $12 \mathrm{~h}$ p.i. These data indicate that production of at least some (insect) toxic secondary metabolites is transient and occurs early in the infection process. Similarly, a cytochrome P450 (CY P52X1), was also highly induced early (18 h p.i.), consistent with its projected role in assimilating host cuticular hydrocarbons and participating in penetration events [7,48]. Expression of the Pdr5 multidrug efflux protein as well as the Pr1 protease, and $\beta-1,3$ glucanase gradually increased 8-12 h p.i., with a peak of expression seen at $18 \mathrm{~h}$ p.i. Expression of the critical protease gene, Pr1, implicated in targeting the host cuticle, was consistent with its function as a cuticle-degrading enzyme, and the Pdr5 membrane efflux protein may act as a means for detoxifying host toxic molecules present on the surface of the insect host. The $\beta-1,3$ glucanase could be functioning in the degradation of host compounds during penetration, although it is not clear what substrates it may be acting on. Alternatively, the enzyme may be important for cell wall remodeling of the fungus, during its dimorphic transition to the production of hyphal bodies once the cuticle has been breached [5,49]. The importance of a B. bassiana GPI anchored-glucanosyltransfaerase has been examined [50], however whether it acts in concert with the $\beta$-glucanase remains to be determined. Intriguingly, the expression of a second cytochrome P450, CYP5293A, was found to peak $24 \mathrm{~h}$ p.i., and although the functions and substrates of this enzyme remain unknown, it is interesting to speculate that distinct hydrocarbon assimilation pathways may be (sequentially) induced depending upon changes and/or access to different host lipids during the infection process. In terms of signaling, the expression of the protein kinase A (cAMP-dependent subunit) and the Hog1 MAP kinase were examined. Our data show a slight elevation of protein kinase A expression early (12 h p.i.), with a more robust responses at $72 \mathrm{~h}$ p.i. In contrast Hog1 MAP kinase expression levels were highest from $24-72 \mathrm{~h}$ p.i. These data indicate that expression levels of the two different fungal signaling pathway components may differentially change during the time course of infection, implying that distinct pathways are triggered at discrete stages. Overall, our data provide a systematic overview of the histopathology of B. bassiana infection of F. occidentalis, and provide new information concerning the expression of key molecular determinants involved in the infection process.

Author Contributions: J.W. and Z.Z. designed the study. Z.Z. carried out most of the work. J.W. and Z.Z. drafted the manuscript. J.W., Z.Z. and C.Z. analysed the data. N.O.K. helped address intellectual content, made critical suggestions for experimental improvement and helped draft the manuscript. Y.G. helped interpretation of data and gave critical suggestions for revising the manuscript. All authors have read and agreed to the published version of the manuscript.

Funding: This work was supported by the China National Natural Science Foundation (Grant No: 31201577), the Doctorial Foundation of Qingdao Agricultural University (Grant No: 630609), and in part by a US National Science Foundation (NSF) grant IOS-1557704 to N.O.K. The funders had no role in study design, data collection and analysis, decision to publish, or preparation of the manuscript. 
Institutional Review Board Statement: Not applicable.

Informed Consent Statement: Not applicable.

Data Availability Statement: Not applicable.

Acknowledgments: The authors are grateful to Thomas Skarlinksy (USDA-APHIS-PPQ, Miami, Florida) for kindly providing the image of F. occidentalis used in graphical abstract and to Baohua Li (Qingdao Agricultural University) for assistance with the frozen sectioning experiments.

Conflicts of Interest: The authors declare no conflict of interest.

\section{References}

1. Cloyd, R.A. Western flower thrips (Thysanoptera: Thripidae) and insecticide resistance: An overview and strategies to mitigate insecticide resistance development. J. Entomol. Sci. 2016, 51, 257-273. [CrossRef]

2. Ortiz-Urquiza, A.; Keyhani, N.O. Stress response signaling and virulence: Insights from entomopathogenic fungi. Curr. Genet. 2015, 61, 239-249. [CrossRef]

3. Ortiz-Urquiza, A.; Keyhani, N.O. Molecular genetics of Beauveria bassiana infection of insects. Adv. Genet. 2016, 94, 165-249.

4. Ortiz-Urquiza, A.; Keyhani, N.O. Action on the surface: Entomopathogenic fungi versus the insect cuticle. Insects 2013, 4, 357-374. [CrossRef]

5. Wanchoo, A.; Lewis, M.W.; Keyhani, N.O. Lectin mapping reveals stage-specific display of surface carbohydrates in in vitro and haemolymph-derived cells of the entomopathogenic fungus Beauveria bassiana. Microbiology 2009, 155, 3121-3133. [CrossRef] [PubMed]

6. Fan, Y.; Liu, X.; Keyhani, N.O.; Tang, G.; Pei, Y.; Zhang, W.; Tong, S. Regulatory cascade and biological activity of Beauveria bassiana oosporein that limits bacterial growth after host death. Proc. Natl. Acad. Sci. USA 2017, 114, E1578-E1586. [CrossRef]

7. Pedrini, N.; Ortiz-Urquiza, A.; Huarte-Bonnet, C.; Zhang, S.; Keyhani, N.O. Targeting of insect epicuticular lipids by the entomopathogenic fungus Beauveria bassiana: Hydrocarbon oxidation within the context of a host-pathogen interaction. Front. Microbiol. 2013, 4, 24. [CrossRef]

8. Santoro, P.; Zorzetti, J.; Constanski, K.; Neves, P.M.O.J. Conidial production, virulence, and stress tolerance of Beauveria bassiana conidia after successive in vitro subculturing. Rev. Colomb. Entomol. 2014, 40, 85-90.

9. Gomes, D.C.; Machado, N.R.; Santi, L.; Broetto, L.; Vainstein, M.H.; Meyer-Fernandes, J.R.; Schrank, A.; Beys-da-Silva, W.O. Inhibition of ecto-phosphatase activity in conidia reduces adhesion and virulence of Metarhizium anisopliae on the host insect Dysdercus peruvianus. Curr. Microbiol. 2013, 66, 467-474. [CrossRef]

10. Ravindran, K.; Qiu, D.; Sivaramakrishnan, S. Sporulation characteristics and virulence of Metarhizium anisopliae against subterranean termites (Coptotermes formosanus). Int. J. Microbiol. Res. 2015, 6, 1-4.

11. Mohan, V.; Nivea, R.; Menon, S. Evaluation of ectomycorrhizal fungi as potential bio-control agents against selected plant pathogenic fungi. J. Acad. Indus. Res. 2015, 3, 408-412.

12. Zhang, S.; Xia, Y.; Kim, B.; Keyhani, N.O. Two hydrophobins are involved in fungal spore coat rodlet layer assembly and each play distinct roles in surface interactions, development and pathogenesis in the entomopathogenic fungus, Beauveria bassiana. Mol. Microbiol. 2011, 80, 811-826. [CrossRef]

13. Kirkland, B.H.; Westwood, G.S.; Keyhani, N.O. Pathogenicity of entomopathogenic fungi Beauveria bassiana and Metarhizium anisopliae to ixodidae tick species dermacentor variabilis, Rhipicephalus sanguineus, and Ixodes scapularis. J. Med. Entomol. 2004, 41, 705-711. [CrossRef]

14. Fan, Y.; Borovsky, D.; Hawkings, C.; Ortiz-Urquiza, A.; Keyhani, N.O. Exploiting host molecules to augment mycoinsecticide virulence. Nat. Biotechnol. 2012, 30, 35-37. [CrossRef]

15. Faria, M.R.; Wraight, S.P. Mycoinsecticides and mycoacaricides: A comprehensive list with worldwide coverage and international classification of formulation types. Biol. Control. 2007, 43, 237-256. [CrossRef]

16. Bielza, P. Insecticide resistance management strategies against the western flower thrips, Frankliniella occidentalis. Pest Manag. Sci. 2008, 64, 1131-1138. [CrossRef]

17. Shipp, J.L.; Binns, M.R.; Hao, X.; Wang, K. Economic injury levels for western flower thrips (Thysanoptera: Thripidae) on greenhouse sweet pepper. J. Econ. Entomol. 1998, 91, 671-677. [CrossRef]

18. Kirk, W.D.J.; Terry, L.I. The spread of the western flower thrips Frankliniella occidentalis (Pergande). Agr. Forest Entomol. 2003, 5, 301-310. [CrossRef]

19. Morse, J.G.; Hoddle, M.S. Invasion Biology of Thrips. Annu. Rev. Entomol. 2006, 51, 67-89. [CrossRef]

20. Zhang, Y.; Wu, Q.; Xu, B.; Zhu, G. The occurrence and damage of Frankliniella occidentalis (Thysanoptera: Thripidae): A dangerous alien invasive pest in Beijing. Plant Prot. 2003, 4, 58-59.

21. Reitz, S.R.; Gao, Y.L.; Kirk, W.D.J.; Hoddle, M.S.; Leiss, K.A.; Funderburk, J.E. Invasion Biology, Ecology, and Management of Western Flower Thrips. Annu. Rev. Entomol. 2020, 65, 17-37. [CrossRef] [PubMed]

22. Wraight, S.P.; Ugine, T.A.; Ramos, M.E.; Sanderson, J.P. Efficacy of spray applications of entomopathogenic fungi against western flower thrips infesting greenhouse impatiens under variable moisture conditions. Biol. Control. 2016, 97, 31-47. [CrossRef] 
23. Ugine, T.A.; Wraight, S.P.; Brownbridge, M.; Sanderson, J.P. Development of a novel bioassay for estimation of median lethal concentrations $\left(\mathrm{LC}_{50}\right)$ and doses $\left(\mathrm{LD}_{50}\right)$ of the entomopathogenic fungus Beauveria bassiana, against western flower thrips, Frankliniella occidentalis. J. Invertebr. Pathol. 2005, 89, 210-218. [CrossRef]

24. Ugine, T.A.; Wraight, S.P.; Sanderson, J.P. Acquisition of lethal doses of Beauveria bassiana by western flower thrips exposed to foliar spray residues of formulated and unformulated conidia. J. Invert. Pathol. 2005, 90, 10-23. [CrossRef]

25. Ansari, M.A.; Brownbridge, M.; Shah, F.A.; Butt, T.M. Efficacy of entomopathogenic fungi against soil-dwelling life stages of western flower thrips, Frankliniella occidentalis, in plant-growing media. Entomol. Exper. Appl. 2008, 127, 80-87. [CrossRef]

26. Skinner, M.; Gouli, S.; Frank, C.E.; Parker, B.L.; Kim, J.S. Management of Frankliniella occidentalis (Thysanoptera: Thripidae) with granular formulations of entomopathogenic fungi. Biol. Control. 2012, 63, 246-252. [CrossRef]

27. Zhang, X.; Wu, S.; Reitz, S.; Gao, Y. Simultaneous application of entomopathogenic Beauveria bassiana granules and predatory mites Stratiolaelaps scimitus for control of western flower thrips, Frankliniella occidentalis. J. Pest Sci. 2021, 94, 119-127. [CrossRef]

28. Duan, Y.L.; Wu, H.; Ma, Z.Y.; Yang, L.; Ma, D.Y. Scanning electron microscopy and histopathological observation of Beauveria bassiana infection of Colorado potato beetle larvae. Microb. Pathog. 2017, 10, 435-439. [CrossRef]

29. Kenneth, J.L.; Thomas, D.S. Analysis of relative gene expression data using real-time quantitative PCR and the $2^{-\Delta \Delta C t}$ method. Methods 2001, 25, 402-408.

30. Hong, M.; Peng, G.; Keyhani, N.O.; Xia, Y. Application of the entomogenous fungus, Metarhizium anisopliae, for leafroller (Cnaphalocrocis medinalis) control and its effect on rice phyllosphere microbial diversity. Appl. Microbiol. Biotechnol. 2017, 101, 6793-6807. [CrossRef]

31. Willmott, A.L.; Cloyd, R.A.; Zhu, K.Y. Efficacy of pesticide mixtures against the western flower thrips (Thysanoptera: Thripidae) under laboratory and greenhouse conditions. J. Econ. Entomol. 2013, 106, 247-256. [CrossRef]

32. Kivett, J.M.; Cloyd, R.A.; Bello, N.M. Insecticide rotation programs with entomopathogenic organisms for suppression of western flower thrips (Thysanoptera: Thripidae) adult populations under greenhouse conditions. J. Econ. Entomol. 2015, 108, 1936-1946. [CrossRef] [PubMed]

33. Vestergaard, S.; Butt, T.M.; Bresciani, J.; Gillespie, A.T.; Eilenberg, J. Light and electron microscopy studies of the infection of the western flower thrips Frankliniella occidentalis (Thysanoptera: Thripidae) by the entomopathogenic fungus Metarhizium anisopliae. J. Inverteb. Pathol. 1999, 73, 25-33. [CrossRef] [PubMed]

34. Holder, D.J.; Keyhani, N.O. Adhesion of the entomopathogenic fungus Beauveria (Cordyceps) bassiana to substrata. Appl. Environ. Microbiol. 2005, 71, 5260-5266. [CrossRef] [PubMed]

35. Toledo, A.V.; de Remes Lenicov, A.M.M.; Lastra, C.C.L. Histopathology caused by the entomopathogenic fungi, Beauveria bassiana and Metarhizium anisopliae, in the adult planthopper, Peregrinus maidis, a maize virus vector. J. Insect. Sci. 2010, 10, 35. [CrossRef]

36. Güerri-Agulló, B.; Gómez-Vidal, S.; Asensio, L.; Barranco, P.; Lopez-Llorca, L.V. Infection of the red plam weevil (Rhynchophorus ferrugineus) by the entomopathogenic fungus Beauveria bassiana: A SEM study. Microsc. Res. Tech. 2010, 73, 714-725.

37. Shabrawy, E.H.A.; Eweis, E.A.; Sewify, G.E.; Naroz, M.H. Investigation of certain stored products insects infected with the entomopathogenic fungi, Beauveria bassiana and Metarhizium anisopliae using scanning electron microscopy. Egypt J. Biol. Pest Cotrol. 2012, 22, 87-92.

38. Liu, Z.; Lei, Z.; Hua, B.; Wang, H.; Liu, T. Germination behavior of Beauveria bassiana (Deuteromycotina: Hyphomycetes) on Bemisia tabaci (Hemiptera:Aleyrodidae) nymphs. J. Entomol. Sci. 2010, 45, 322-334. [CrossRef]

39. James, R.R.; Buckner, J.S.; Freeman, T.P. Cuticular lipids and silverleaf whitefly stage affect conidial germination of Beauveria bassiana and Paecilomyces fumosoroseus. J. Invertebr. Pathol. 2003, 84, 67-74. [CrossRef]

40. Wang, C.; St Leger, R.J. The MAD1 adhesin of Metarhizium anisopliae links adhesion with blastospore production and virulence to insects, and the MAD2 adhesin enables attachment to plants. Eukaryot. Cell. 2007, 6, 808-816. [CrossRef]

41. Liu, W.; Xie, Y.; Xue, J.; Zhang, Y.; Zhang, X. Ultrastructural and cytochemical characterization of brown soft scale Coccus hesperidum (Hemiptera: Coccidae) infected by the Lecanicillium lecanii(Ascomycota: Hypocreales). Micron 2011, 42, 71-79. [CrossRef] [PubMed]

42. Schreiter, G.; Butt, T.M.; Beckett, A.; Vestergaard, S.; Moritz, G. Invasion and development of Verticillium lecanii in the western flower thrips, Frankliniella occidentalis. Mycol. Res. 1994, 98, 1025-1034. [CrossRef]

43. Gao, Y.; Xie, Y.; Xiong, Q.; Liu, W.; Xue, J. Ultrastructural exploration on the histopathological change in Phenacoccus fraxinus infected with Lecanicillium lecanii. PLoS ONE 2015, 10, e0117428. [CrossRef]

44. Cito, A.; Barzanti, G.P.; Strangi, A.; Francardi, V.; Zanfini, A.; Dreassi, E. Cuticle-degrading proteases and toxins as virulence markers of Beauveria bassiana (Balsamo) Vuillemin. J. Basic Microbiol. 2016, 56, 941-948. [CrossRef] [PubMed]

45. Wu, S.; Gao, Y.; Zhang, Y.; Wang, E.; Xu, X.; Lei, Z. An entomopathogenic strain of Beauveria bassiana against Frankliniella occidentalis with no detrimental effect on the predatory mite Neoseiulus barkeri. evidence from laboratory bioassay and scanning electron microscopic observation. PLoS ONE 2014, 9, e0084732.

46. Dikgolz, V.E.; Toledo, A.V.; Topa, P.E.; Lastra, C.C.L. Evaluation of histological techniques for the detection of fungal infections caused by Leptolegnia chapmanii (Oomycetes: Saprolegniales) in Aedes aegypti (Diptera: Culicidae) larvae. Folia Microbiol. 2005, 50, 125-127. [CrossRef]

47. Gao, T.; Wang, Z.; Yü, H.; Keyhani, N.O.; Huang, Z. Lack of resistance development in Bemisia tabaci to Isaria fumosorosea after multiple generations of selection. Sci. Rep. 2017, 7, 42727. [CrossRef] 
48. Zhang, S.; Widemann, E.; Bernard, G.; Lesot, A.; Pinot, F.; Pedrini, N.; Keyhani, N.O. CYP52X1, representing new cytochrome P450 subfamily, displays fatty acid hydroxylase activity and contributes to virulence and growth on insect cuticular substrates in entomopathogenic fungus Beauveria bassiana. J. Biol. Chem. 2012, 287, 13477-13486. [CrossRef]

49. Lewis, M.W.; Robalino, I.V.; Keyhani, N.O. Uptake of the fluorescent probe FM4-64 by hyphae and haemolymph-derived in vivo hyphal bodies of the entomopathogenic fungus Beauveria bassiana. Microbiology 2009, 155, 3110-3120. [CrossRef]

50. Zhang, S.; Xia, Y.; Keyhani, N.O. Contribution of the gas1 gene of the entomopathogenic fungus Beauveria bassiana, encoding a putative glycosylphosphatidylinositol-anchored beta-1,3-glucanosyltransferase, to conidial thermotolerance and virulence. Appl. Environ. Microbiol. 2011, 77, 2676-2684. [CrossRef] 